\title{
Nutrition Policy and Practice Landscape on Adolescent, Pre Pregnancy and Maternal Nutrition in Nigeria
}

\author{
Adinma JIB ${ }^{1 *}$, Adinma $\mathrm{ED}^{2}$ and Umeononihu $\mathrm{OS}^{1}$ \\ ${ }^{1}$ Department of Obstetrics and Gynaecology, Nnamdi Azikiwe University and Teaching Hospital, Nigeria \\ ${ }^{2}$ Department of Community Medicine, Nnamdi Azikiwe University and Teaching Hospital, Nigeria
}

Submission: March 15, 2017; Published: April 27, 2017

*Corresponding author: JIB Adinma, Department of Obstetrics and Gynaecology, Nnamdi Azikiwe University and Teaching Hospital, Nnewi, Anambra State, PMB: 5025 Nnewi, Nigeria, Tel:+2348037080814; Email: brianadinma@yahoo.com/br.adinma@unizik.edu.ng

\begin{abstract}
Background: Nutrition has impact on human growth and development at all stages of life. Optimal nutrition at every stage of life is therefore a fundamental human right.

Objectives: To review the status of adolescent, pre-pregnancy and maternal (APM) nutrition in Nigeria, in respect of Nutrition policy and practice landscape and makes recommendation towards the promotion of APM nutrition in Nigeria.

Methodology: Review of relevant literature, and internet search, on Nutrition in Nigeria, including the review of Nigeria Food and Nutrition Policy vid the health sector component, and FIGO Recommendation on Adolescent, Preconception, and Maternal Nutrition.

Result: Approximately 14million (8.5\%) of Nigerian population are undernourished. Up to $37 \%$ of all children under-five in Nigeria are classified as stunted. Micronutrient deficiency (Vitamin A, Iodine, Iron and Zinc) are common in Nigeria. The NDHS of 2013 showed that under nutrition occurred in $23 \%$ of adolescent girls aged 15-19 years and that under nutrition was more prevalent among the rural women, $13 \%$, compare to urban dwellers, $10 \%$. Anaemia occurs in $35-75 \%$ of pregnant women in Nigeria. The Nigeria Strategic Plan of Action for Nutrition focused primarily on promoting nutrition during the first 1,000 days of life and made no reference to APM Nutrition. There are no nutrition intervention policies and practices directed at the adolescent and pre-pregnant. Total energy intakes among adolescent, pregnant and postpartum women are carbohydrate driven. Protein is of plant origin mainly from legumes, fat is obtained from red palm, and vegetable, oil. Food restriction and inappropriate food preparation habit commonly occur amongst pregnant mothers in Nigeria. Exclusive breastfeeding of the infant during the first six months of life has been recommended. FIGO expert committee on APM nutrition developed a set of recommendations on Adolescent, Pre-pregnancy and Maternal Nutrition, for local adaptation.
\end{abstract}

Conclusion: APM Nutrition in Nigeria is poorly developed with few interventions. Promotion of APM nutrition will require a revision of the Nigeria strategic plan of action for nutrition to include interventions targeted at the adolescent, pre-pregnant, pregnant and postpartum women; Mobilisation of all stakeholders on nutrition towards nutrition intervention, advocacy and action; Quantification of the caloric value of foods consumed locally together with the Identification of the domicile of relevant micronutrient in local foods; Local adaptation of FIGO recommendation on APM Nutrition; and Development of Nutritional guidelines, and IEC materials relevant to the adolescent, pre-pregnancy, pregnancy and post-partum period.

\section{Introduction}

Nutrition constitutes an important contemporary global feature on account of its impact on human growth and development at all stages of life [1]. Good nutrition refers to a well-balanced diet that provides all essential nutrients in optimal amounts and proportions, while Malnutrition is a situation of nutritional imbalance due to inadequate intake of macronutrients (calories and proteins) (under nutrition), and in some cases including micronutrients - multi vitamins and minerals, and also includes the intake of nutrient-poor diet in spite of excess calorie -Over nutrition/Obesity [1].

Optimal nutrition at every stage of lifecycle is a fundamental human right. Malnutrition is therefore considered to constitute a denial of that right. The spectra of malnutrition - under nutrition and over nutrition both have deleterious impact onto human beings. Under nutrition is believed to account for approximately 1.5 million global maternal and child death annually, while 
over nutrition contribute immensely to global morbidity and mortality from diet related non-communicable diseases notably diabetes and hypertension [2]. Poor nutrition has a linkage with several socio-economic factors and is therefore of particular significance to the health of the poor and vulnerable segment of the population notably women and children, especially those living in developing countries of Sub-Saharan Africa.

Nutrition and its importance to women's health has attracted global recognition, being captured in atleast five of the eight goals of United Nation Millenium Development Goals (MDGs) [3] and in the second target of the second goal of the Sustainable Development Goals (SDGs) [4]. Furthermore the International Federation of Gynaecology and Obstetrics (FIGO), at its 21st World Congress of Obstetrics and Gynaecology launched a set of recommendation on Adolescent, Pre-pregnancy and Maternal Nutrition developed by its expert committee and other stakeholders on nutrition [5]. The short review examines the status of adolescent, pre-pregnancy and maternal nutrition in Nigeria, Vis-a-Vis Nutrition policy and practice landscape and makes recommendation towards the promotion of adolescent, pre-pregnancy and maternal nutrition in Nigeria.

\section{Profile of Nutrition in Nigeria}

Nigeria has a land mass of 923,768 square kilometre. With a December 2016 population estimate of 193 million [6]. Nigeria remains the most populous country in Africa and harbours the highest concentration of black people in the world $[7,8]$. Nigeria Consist of six geo-political zones; 36 states with a Federal Capital Territory; and 774 Local Government Areas (LGAs) [7]. Fourth-eight percent of her people are urban dwellers while the remaining 52\% are rural [7]. Approximately 14 million people representing $8.5 \%$ of total population of Nigerians are undernourished [9]. Nigeria has the highest number of stunted children under age five in sub-Saharan Africa, and the second highest in the world, with $37 \%$ of all children under five classified as stunted. The 2013 Nigeria Demographic and Health Survery (NDHS) data revealed the immediate causes of under nutrition in Nigeria include micronutrients deficiency such as Vitamin A, Iodine, Iron and Zinc. Approximately 30\% and 20\% of under-fives are deficient respectively of Vitamin A and Zinc. As high as $63 \%[1,7]$ of women are anaemic, while $31 \%$ have iodine deficiency. Under nutrition was more marked in the three geo-political zones of the northern state of Nigeria - North East, North West and North Central including the Federal Capital Territory and occurred more among rural compare to Urban dwellers. The most obvious causes of malnutrition in Nigeria include poor infant and child feeding practices, lack of access to healthcare, water, and sanitation, and a high level of poverty [1].

An alarming rise in the incidence of Diet related Noncommunicable diseases is also being currently observed in Nigeria alongside high rate of under nutrition. In Nigeria, the NDHS of 2008 reported that $22 \%$ of women were overweight or obese, with the frequency increasing with age, education and wealth [10]. The NDHS data of 2013 revealed an increase in over nutrition from $21 \%$ (2003) to $25 \%$ (2013) [7,11]. Increase in DRNCD has being attributed to Globalisation, Urbanisation, Lifestyle Transition, Socio-cultural factors, and poor maternal, foetal and infant nutrition [1].

\section{Nutrition Policy and Practice Landscape in Nigeria}

\section{Evolution of Nutrition Policy in Nigeria}

Before 1990, Food and Nutrition activities in Nigeria were carried out sectorally with multiple sector based policies which did not conform to UNICEF Conceptual Framework on the causes of malnutrition1. Activities based on these policies were limited in scope, uncoordinated and ineffective in addressing nutritional problems comprehensively. In 1990, the Federal Government of Nigeria established the National Committee on Food and Nutrition (NCFN) which was charged with the responsibility of developing a comprehensive policy and action plan on elimination of malnutrition in Nigeria.Originally domiciled in Ministry of Science and Technology, the NCFN moved to Ministry of Health in 1993 and to National Planning Commission in 1994.

In 1995 NCFN developed the National Food and Nutrition Policy (NFNP) which was approved by the federal government of Nigeria in 1998 and ultimately launched in 2002.

\section{The specific target of NFNP include}

A. Reduction of severe and moderate malnutrition among children under five by $30 \%$ by 2010 , and

B. Reduction of micronutrient deficiencies (principally of vitamin A, iodine, and iron) by $50 \%$ by 2010 .

\section{The specific Intervention based on National Food and Nutrition Policy include}

A. Fortification of foods which resulted in Vitamin A fortification of $70 \%$ Sugar, $100 \%$ wheat flour and 55\% Vegetable oil and iron fortification of wheat flour.

B. Establishment of Home-Grown School Feeding and Health Programme under the Ministry of Education in September 2005.

C. Establishment of 495 community site for the management of severe acute malnutrition.

D. Conduct of first Nutrition Summit, in 2012, to create a Roadmap towards Scaling up Nutrition in Nigeria" which recommended the promotion of infant feeding practices; vitamin and mineral supplementation to control micronutrient deficiency; food fortification and dietary diversification, salt iodisation programme to eliminate iodine deficiency, and recognising the role other sectors played in improving food security.

E. Establishment of inter-ministerial/multi sectoral Nutrition Partners Forum that meets four times annually to review, deliberate and strategize on nutrition issues. 
National Strategic Plan of Action for Nutrition (Nspan) 2014- 2018

NSPAN was formulated as a guide for action for the Health sector component of the National Food and Nutrition Policy. It focuses substantial attention to improving nutrition during the first 1,000 days (from pregnancy to 24 months old) [1]. Its specific objectives focuses on

A. Promoting effective delivery of nutrition intervention

B. Control of diet related non-communicable diseases.

C. Promotion and strengthening of nutrition research, monitoring and evaluation.

D. Facilitating community participation for nutrition intervention and

E. Promoting and strengthening nutrition coordination and collaboration.

\section{Adolescent, Pre-Pregnancy and Maternal Nutrition in} Nigeria

\section{Nutrition during Adolescent and Pre-conception}

The Nigerian Demographic and Health Survey of 2013 revealed that $23 \%$ of the adolescent girls (age 15 - 19 years) were undernourished and that under nutrition was more prevalent among the rural women, $13 \%$, compare to urban dwellers, $10 \%$ [7].

Total Energy intake among adolescent is Carbohydrate driven. Derived mainly from roots and tubers. Protein is mainly of vegetable origin derived from cowpea, groundnut and cerealsmostly from snacks. Fat is derived mainly from consumption of red palm oil/vegetable oil [12]. Iron is also mainly of plant origin and has low bioavailability because of absorption inhibitory effect of tannins and phytates. Vitamin A intake is usually sufficient - mainly from consumption of red palm oil and carrots. There are no local policies and practices specific to the adolescent and pre-pregnant women. These represent a huge nutrition gap for this very important segment of the population.

\section{Nutrition during pregnancy}

The pattern of food consumed in terms of carbohydrate, fat and protein are similar during pregnancy as in the nonpregnancy state.However, Food restrictions (taboos) are essential characteristics of nutrition during pregnancy in Nigeria as it is in some other West African countries [13-15]. It commonly occurs in association with primigravidity; teenage pregnancy; lack of formal education and low household income [14]. Most commonly restricted foods include protein and vegetable [16]. The pregnant woman in Nigeria also characteristically consumes leafy green vegetables which has adequate mineral and vitamin content $[17,18]$. Certain food preparation habit are inimical to appropriate good nutrition during pregnancy in Nigeria. This include parboiling of rice, blanching and over stewing of vegetables. A foremost manifestation of poor nutritional habit during pregnancy in Nigeria is anaemia which occurs in 35\% $75 \%$ of pregnant women in Nigeria $[1,7,19,20]$. Anaemia during pregnancy usually result from a combination of nutritional deficiency, malaria, hookworm infestation and other diseases such as urinary tract infection. Policy and practices put in place to check the ravages of under nutrition and morbidity during pregnancy include early antenatal booking and good antenatal care; iron and folic acid supplementation during pregnancy; malaria prophylaxis using sulphadoxine-pyremethamine (SP drugs) and Sleeping under insecticide treated bed-net; malaria treatment using arthemisinine based combination therapy (ACT); treatment of hookworm infestations using anti-helminthics drugs and treatment of urinary tract infections using antibiotics, when appropriate; and uncoordinated nutritional counselling and education as part of antenatal care health education [21].

\section{Nutrition during Postpartum}

The postpartum period with lactation represents another era of increased nutritional demands for the mother. Postpartum food intake in most part of Nigeria is of poor quality bothering on over nutrition due to high consumption of carbohydrate from roots and tubers. Protein, fat, fruits and vegetables are consumed in sub-optimal amount [22]. In some cultures there is also intake of peppery foods, hot spices and alcohol believed to enhance the egress of lochial. Native white palm wine is also consumed in copious amount, believed to promote the production and flow of breast milk $[12,13]$. There are no formal local practices put in place for the mother on postpartum nutrition. Exclusive breast feeding for the infant during the first six months of life is a policy that has been universally promoted in Nigeria, although the practice is yet to gain wide spread acceptability $[1,12,13,23]$.

Figo Initiative on Adolescent, Pre-Pregnnacy and Maternal Nutrition

FIGO expert group in collaboration with other stakeholders were able to developed evidence based recommendation on Adolescent, Pre-pregnant and Maternal Nutrition which was launched at the 21st FIGO World Congress of Obstetrics and Gynecology in Vancover, Canada, in October 2015 [5].

\section{The key principles of FIGO recommendation includes the following}

A. Paying Greater attention to the links between poor maternal nutrition and non communicable diseases;

B. Considering Adolescent, preconception and maternal nutrition using a life course approach.

C. Supporting women from the time of planning a pregnancy right through to the post-partum period;

D. Focusing on both the woman and the newborn

E. Dispeling food-related myths; 
F. Discussing both under-nutrition and obesity.

G. Highlighting the impact that various micronutrients have on the wellbeing of women and the development of the foetus and newborns and

H. Promoting a wide range of healthcare providers working together, with a focus on nutrition, health, and lifestyle.

\section{FIGO Recommendations}

FIGO adopted the slogan "Think Nutrition First" for the propagation and promotion of its recommendation on Adolescent, Pre-pregnancy and Maternal Nutrition. FIGO furthermore appointed 14 regional ambassadors charged with the responsibility of adapting and promoting these recommendations the world over. The summary of this recommendation include the following:

1. In general - promotion of a varied and healthy diet as the first step to meeting the nutrient needs of adolescent girls and women, with the provision of supplements or fortified foods when necessary

2. Malnutrition should be viewed as poor nutrition in all its forms, from both deficient (energy and protein under nutrition) or excessive (obesity) consumption of macronutrients, to micronutrient malnutrition. This results from a diet with insufficient vitamin and mineral density, poor bioavailability of nutrients, or increased body requirements due to infection or growth. Malnutrition can result from overconsumption of nonnutritive calories - food quality counts as much as food quantity

3. Micronutrient deficiencies should recognized and rectified through interventions, including dietary diversity, consumption of fortified foods, and supplementation as appropriate.

a. FIGO's recommendations document contains a table with recommended micronutrient intake for pre-pregnant, pregnant and lactating stages.

b. Key micronutrient under consideration includes the following:

i. Iron: adolescent girls and pregnant women are at risk of iron deficiency due to menstrual blood loss and increased pregnancy demands, and commonly require iron supplements

ii. Iodine: required early in pregnancy and often lacking in diets if iodized salt is not used

iii. Folate: required before conception and in early pregnancy as dietary intake is usually inadequate; all women of reproductive age are advised to consume $400 \mu \mathrm{g}$ of folic acid per day as supplements or fortified foods.

iv. Vitamin B12: Dietary intake is very low in vegetarian diets and absent in vegan diets v. Calcium: Lacking in diets low in dairy products; there is a higher requirement, especially in adolescents during the growth spurt

vi. Vitamin D: food sources are minimal unless fortified, and inadequacy is common, especially in women with minimal sun exposure or darkly pigmented skin.

Adolescent and Pre-conception life stages

a. FIGO emphasizes the importance of optimizing the nutritional status of adolescent girls and women and encouraging the adoption of good dietary and lifestyle habits before pregnancy.

b. FIGO recommends that attention be paid to preconception body weight and BMI as modifiable risk factors with important effects on a woman's nutritional status:

i. Underweight women may be lacking in a number of important nutrients, and their diets should be carefully assessed and supplemented as required.

ii. Overweight or obese women may have poor diets that are high in energy but low in nutritional value.

Pregnant woman

a. FIGO strongly recommends that pregnant women should have early access to prenatal care to receive appropriate nutrition counselling and interventions, and treatment for conditions that jeopardize their pregnancy outcome, such as malaria, tuberculosis, HIV, gastrointestinal infections, and non communicable diseases.

Post-Pregnancy Period

a. FIGO recommends that the period that follows birth is used to improve the nutritional status of both mother and child. FIGO endorses the WHO recommendation of exclusive breastfeeding for the first 6 months of the infant's life [5].

Society of Gynecology and Obstetrics of Nigeria (SOGON) is playing a major role towards adaptation and implementation of FIGO recommendation on Adolescent, Pre-pregnancy and Maternal Nutrition (APM) through advocacy presented to stakeholders at various conferences and fora both in Nigeria and in other countries of Africa. Efforts are also being made towards the quantification of the caloric value of foods consumed in the country as well as the identification of the domiciled of micronutrients in these foods. This will be expected to form an accurate adaptation of FIGO recommendation on APM Nutrition to local needs. It is expected that guidelines will ultimately be develop to guide healthcare providers at all levels including the primary health centers as to effective counselling of adolescent girls and mothers on good nutrition appropriate to the adolescence, preconception, pregnancy and postpartum periods. 


\section{Conclusion and Recommendation}

Adolescence, Pre-Pregnancy and Maternal Nutrition in Nigeria are poorly developed with very few organised interventions.

The National Food and Nutrition Policy made little or no reference whatsoever to the nutrition of this vital segment of the Nigerian population. The National Strategic Plan of Action for Nutrition culled from the National Food and Nutrition Policy was developed to promote effective delivery of nutrition intervention; control diet related non-communicable diseases; promote and strengthen nutrition research, monitoring and evaluation; facilitate community participation for nutrition intervention and promote and strengthen nutrition coordination and collaboration in Nigeria. This strategic plan of action however was essentially focused on the promotions of intervention during the first 1,000 days of life -from pregnancy to 24 months of live. Promoting Adolescent, Pre-pregnancy and Maternal (APM) nutrition will require a revision of the Nigeria strategic plan of action for nutrition to include interventions targeted at the adolescent, pre-pregnant, pregnant and postpartum women; Mobilisation of all stakeholders- government, non-governmental organizations, Obs/Gyn practitioner, nurses, nutritionist, primary health care practitioner, schools, communities etc towards effective advocacy andaction on APM Nutrition; Quantification of the caloric value of foods consumed locally together with the Identification of the domicile of relevant micronutrient in local foods; Local adaptation of FIGO recommendation on APM Nutrition and Development of Nutritional guidelines, and IEC materials relevant to the adolescent, pre-pregnancy, pregnancy and post-partum period.

All stakeholders are expected to "Think Nutrition first" to improve the nutritional well-being and health of girls, women, their children and the society at large.

\section{References}

1. WHO Health topics: Nutrition. World Health Organisation, Geneva, Switzerland

2. WHO (2014) Food and Agriculture Organization World Health Organization. Second International Conference on Nutrition. WHO, Geneva, Switzerland.

3. United Nation Children's Funds: Millennium Development Goals (MDGs).

4. Sustainable Development Knowledge Platform.

5. Mark AH, Anne B, Luz MD, Sophie EM, Emily O, et al. (2015) The International Federation of Gynecology and Obstetrics (FIGO) recommendations on adolescent, preconception, and maternal nutrition: Think Nutrition First. Int J Gynaecol Obstet 131(4): S213-S253.
6. National Bureaus of Statistics (NBS) and National Population Commission (NPC).

7. National Population Commission (NPC) [Nigeria] and ICF International. 2014. Nigeria Demographic and Health Survey 2013. Abuja, Nigeria, and Rockville, Maryland, USA: NPC and ICF International.

8. (2015) World Bank, Urban and Rural population.

9. FAO, WFP, IFAD (2012) The State of Food Insecurity in the World 2012. Economic growth is necessary but not sufficient to accelerate reduction of hunger and malnutrition. Rome, Italy.

10. National Population Commission [Nigeria], ICF Macro (2009) Nigeria Demographic and Health Survey 2008 (NDHS). National Population Commission and ICF Macro, Abuja, Nigeria.

11. National Population Commission (NPC) [Nigeria] (2003) Nigeria Demographic and Health Survey 2003.

12. Adinma JIB (2016) Thinking Nutrition First: For the Promotion of Adolescent, Pre-pregnancy and Maternal Health. Paper presented at 14eme Congres de la SocieteAfricaine de GynecologieObstetrique (SAGO), 8eme Congres de la Societe des Gynecologues et Obstetriciens du Burkina (SOGOB), Ouagadougou.

13. Adinma JIB (2016) Overview of and Nigeria Perspective on Adolescent, Pre-pregnancy and Maternal Nutrition. Paper presented at $56^{\text {th }}$ Annual General of Society and Gynecologist of Nigeria, Akure, Nigeria.

14. Oni OA, Tukur J (2012) Identifying pregnant women who adhere to food taboos in a rural community: a community-based study. Afr J Reprod Health 16(3): 68-76.

15. Huybregs LF, Roberfroid DA, Kolsteren PW, Van Camp JH (2009) Dietary behaviour, food and nutrient intake of pregnant women, in a rural community in Burkina Faso. Matern Child Nutr 5(3): 211- 222.

16. ORC Macro (2005) Africa nutrition Chart books. Nutrition of young children and mothers in Ghana: findings from the 2003 Ghana Demographic and Health Survey. Calverton, Maryland, USA.

17. Sholeye 00, Catherine AB, Olubukunola AJ (2014) Dietary habit of pregnant women in Ogun-East senatorial zone, Ogun state, Nigeria: A comparative study 6(4): 42-49.

18. Madiforo AN (2010) Superstitions and nutrition among pregnant women in Nwangele Local Government Area of Imo State, Nigeria. J Res Nat Dev 8(2): 16-20.

19. Badi SH, Dabels N, Jibung GG (2012) Medicinal value of vegetable consumption among Berom pregnant women. Asian J Med Sci 4(3): 86-88.

20. Omigbodun AO (2004) Recent trends in the management of anaemia in pregnancy Tropical Journal of Obstetrics and Gynaecology 21(1): $1-3$.

21. Olujimi A, Olatunbosun I, Aniekan M, Abasiattai I, Godwin, et al. (2014) Prevalence of Anaemia among Pregnant Women at Booking in the University of Uyo Teaching Hospital Uyo, Nigeria. BioMed Research International, p. 8.

22. Ukegbu Patricia Ogechi (2014) A Study of the Nutritional Status and Dietary Intake of Lactating Women in Umuahia, Nigeria. American Journal of Health Research 2(1): 20-26.

23. Sanusi RA, Falana OA (2009) The nutritional status of mothers practicing breastfeeding. Afr J Biomed Res 12. 

(c) (i) This work is licensed under Creative
Your next submission with Juniper Publishers will reach you the below assets

- Quality Editorial service

- Swift Peer Review

- Reprints availability

- E-prints Service

- Manuscript Podcast for convenient understanding

- Global attainment for your research

- Manuscript accessibility in different formats

( Pdf, E-pub, Full Text, Audio)

- Unceasing customer service

Track the below URL for one-step submission https://juniperpublishers.com/online-submission.php 